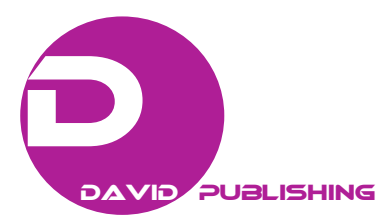

\title{
Prostate Cancer in Keffi Metropolis, Nasarawa State, Nigeria. A Histopathological Analysis
}

\author{
Oluwole Olabode Peter ${ }^{1}$, Abimiku Bawa Ahmed ${ }^{1}$, Adeosun OluseyiAdemola ${ }^{2}$ and Omoregie Peter Oziegbe ${ }^{2}$ \\ 1. Department of Pathology/Forensic Medicine, University of Abuja Teaching Hospital, Gwagwalada, Abuja, Abuja, F.C.T. 900001, \\ Nigeria \\ 2. Department of Surgery, Federal Medical Centre, Keffi, Nasarawa State 961101, Nigeria
}

\begin{abstract}
BACKGROUND: Prostate cancer continues to be a major public health issue and efforts to address the global prostate cancer disparities in Black males are met with many challenges, specifically in developing nations. OBJECTIVE: To show that prostate cancer is common cause of morbidity, mortality and to analyse the pattern of distribution of the disease. METHODS: This is a 4-year retrospective histopathological analysis of prostate cancer specimens diagnosed between January 2006-December 2009 in the Department of Pathology, Federal Medical Centre, Keffi, Nasarawa State. Haematoxylin \& Eosin (H\&E) stained histology slides were retrieved and studied. The slides were reviewed by two consultant pathologists blinded; they were in agreement over the diagnosis. The parameters studied were histological type of cancer, patient's age and the trend over a 4-year period. After histological assessment, the tumour was classified according to WHO recommendation. Histological grading and scoring of adenocarcinoma was done using Gleason System. RESULTS: Forty-One (41) cases of prostate cancer were reviewed during the period of study. The surgical procedure were prostatectomy $23(56 \%)$ and trucut biopsy 18 (44\%). The age range was between 50-89 years with a mean of 69.5 years. The peak age at diagnosis was in the eighth decade. Most of the adenocarcinoma in this analysis was incidental carcinoma as most of the patients were thought to have nodular hyperplasia, but they were found to have adenocarcinoma on histological examination. The Gleason scores range from 4 to 10 . There were 7 (17\%) cases of well differentiated-, $22(53.7 \%)$ patients had moderately differentiated-, while $12(29.3 \%)$ patients had poorly differentiated adenocarcinoma. No other histological types were seen. CONCLUSION: Though a lot had been done to improve the quality of care of patients with prostate cancer, there is still much to done in developing countries as most of the recent available modalities of treatment cannot be accessed due to a high cost and lack of access to health insurance.
\end{abstract}

Key words: Prostate cancer, incidental carcinoma, cancer burden.

\section{Introduction}

Apart from skin cancer, prostate cancer is the most frequently diagnosed cancer and the second leading cause of death as a result of cancer for men in the United States [1, 2]. However, incidence and mortality rates for this disease vary substantially among geographic areas and ethnic groups. Most notably African American men (AA) in the United States have the highest risk (19\%) of developing prostate cancer, and due to the development of more aggressive disease, they have more than twice the mortality rate observed for other racial and ethnic groups [3].

Corresponding author: Olabode Peter Oluwole, M.B.B.S, FMCPath, associate professor, research field: genitourinary pathology, breast cancer.
Differences in prostate cancer incidence between men of different geographic origins is not unique to the United States alone; for example, in Sao Paulo, Brazil, prostate cancer is 1.8 times more common in Brazilians of African than European descent [4].

The worldwide differences in the incidence of prostate cancer and the noticeable variations among ethnic groups were noted by Gronberg [5] to be caused by multiple factors, including genetic susceptibility, external risk factors, health differences and cancer registration.

In addition to the above factors, Odedina et al. [6] have noted some health behavioural factors like, perceived susceptibility of getting prostate cancer, perceived severity of the disease and sequelae, 
perceived benefits about reducing the risk of disease; perceived barriers impacting early disease detection and prevention behaviours, cues to action in activating preventive and early detection measures and perceived behavioural control as among other factors impacting on the burden of this disease among Black men.

\section{Materials and Methods}

This is a 4-year retrospective histopathological analysis of prostate cancer diagnosed between January 2006-December 2009 in the Department of Pathology, Federal Medical Centre, Keffi, Nasarawa State. After histological assessment, the tumours were classified based on WHO classification of Prostatic tumours. Histological grading was done using Gleason grading system.

\section{Results}

Forty-One (41) cases of prostate cancer were reviewed. The age range was between $50-89$ years with a mean of 69.5 years (Table 1 ).

The peak age at diagnosis was in the eighth decade. The surgical procedures were prostatectomy $23(56 \%)$ and trucut biopsies 18 (44\%).

Most of the adenocarcinoma in this analysis was incidental carcinoma as most of the patients were thought to have nodular hyperplasia, but they were found to have adenocarcinoma on histological examination.

The Gleason scores ranges from 4 to 10 . There were 7 (17\%) cases of well differentiated-, $22(53.7 \%)$ patients had moderately differentiated-, while 12 (29.3\%) patients had poorly differentiated adenocarcinoma. No other histological types were seen.

Table 1 Age distribution of prostate cancer patients.

\begin{tabular}{ll}
\hline Age-group & Frequency $(\%)$ \\
\hline $50-59$ & $3(7.3)$ \\
$60-69$ & $10(24.5)$ \\
$70-79$ & $20(48.8)$ \\
$80-89$ & $7(17.0)$ \\
Unspecified & $1(2.4)$ \\
Total & $41(100 \%)$ \\
\hline
\end{tabular}

\section{Discussion}

Prostate Cancer has become the number one cancer in men with increasing incidence and morbidity in men of black African ancestry [7]. Its incidence and prevalence in black men is in multiples of those from other races in several studies [8].

Black men continue to be disproportionately affected by prostate cancer and have the highest morbidity and mortality rates for prostate cancer. According to the American Cancer Society [1], blacks have 1 in 5 lifetime probability of developing invasive prostate cancer compared to 1 in 7 for whites.

The lifetime probability of dying from invasive prostate cancer is 1 in 23 for black men and 1 in 38 for white men. Black men also experience disparities relative to prostate cancer survival with an overall 5-year survival rate of $95 \%$ for black men and $100 \%$ for white men [1]. The Black racial/ethnic group is the only group that has not met the Healthy People 2010 goal of reducing prostate cancer mortality rate to 28.8/100,000 by 2010 [1].

Although, the racial factor have been implicated, there is no defined biologic basis for this, as these differences in morbidity and mortality rates are more likely to reflect a difference in factors like environmental exposure, diet, lifestyle, and health-seeking behaviour rather than any racial susceptibility to prostate cancer [9].

Within the African continent, previous reports have indicated that prostate cancer is uncommon in African men [10]. However, in recent years; attention has focused predominantly on prostate cancer because of the perceived high incidence of prostatic carcinoma in different geographical areas worldwide [11].

Jackson et al. [12] were among pioneering investigators who showed that the incidence of invasive prostatic carcinoma was five times higher in autopsies from black men in Washington DC than in necropsy material from Ibadan, Nigeria.

Solanke [13] was foremost in bringing into focus the realization that in Nigeria prostate cancer has probably 
assumed the position of being the leading cause of cancer mortality in men. However, Ogunbiyi and Shittu [14] recently reported that prostate cancer has now emerged as the most common cancer in Nigerian men.

Across Africa, there has been a shift from the earlier assertions that prostate cancer was rare in Africans. In South African men [15], Ugandans [16] and white Zimbabweans [17] showed similar trend when Kaposi's sarcoma and skin cancers are excluded in the two populations.

The age range of 50-89 years with the mean of 69.5 years in this report is similar to what Ogunbiyi and Shittu [14] reported in Ibadan, but differs from what was found in Zaria [18].

The peak age incidence in this study was in the eighth decade, this similar to studies in America [19] and in Zaria [18], Nigeria.

There were two surgical procedures, prostatectomies $23(56 \%)$ and trucut biopsies 18 (44\%).

This showed that $56 \%$ of the prostate cancer in this review was incidental carcinoma; incidental carcinoma has been shown to vary with age and sectioning technique. Studies from Kenya [20], Benin [21] and Zaria [18] had similar findings, although, their percentages were in the range of $11.9 \%$ to $35.1 \%$.

The Gleason score ranges from 4 to 10 . There were seven $(17.0 \%)$ cases of well differentiated adenocarcinoma, twenty-three $(53.7 \%)$ cases of moderately differentiated adenocarcinoma; and twelve (29.3\%) cases of poorly differentiated adenocarcinoma. This differs from studies from Zaria [18] and Lokoja [22], where no well-differentiated adenocarcinoma was found, but is in agreement with other hospital based studies from Benin [21] and Kenya [20].

In conclusion, prostate cancer is common and stills a burden in Nigeria as many of our men are fully aware of this disease. There is need to make men to be aware of prostate cancer and made them subject themselves to prostate specific antigen (PSA) screening test. There is need for the government to increase funding to health in order to make the screening test available and affordable to all, so that many men who cannot afford the test can come out en-mass for the screening. Moreover, there is need for collaboration between centres in Nigeria to form a prostate cancer network group that will work in synergy to form a national data base for prostate cancer in Nigeria. We also need to form international collaboration with partners abroad to assist us modern ancillary diagnostic techniques like immunohistochemistry and cytogenetic studies to help improve our diagnostic acumen.

\section{References}

[1] American Cancer Society: Cancer Facts \& Figures for African Americans. 2009-2010. American Cancer Society, Atlanta, GA; 2009. Accessed January 20, 2016. www.cancer.org

[2] American Cancer Society: Cancer Facts \& Figures. 2010. American Cancer Society. Atlanta, GA; 2010. Accessed January 20, 2016. www.cancer.org

[3] American Cancer Society. Cancer Facts \& Figures. 2008. American Cancer Society, Atlanta, GA; 2008. Accessed January 20, 2016. www.cancer.org

[4] Bouchardy, C., Mirra, A. P., Khlat, M., Parkin, D. M., de Souza, J. M., and Gotlieb, S. L. 1991. "Ethnicity and Cancer Risk in Sao Paulo, Brazil." Cancer Epidemiol. Biomarkers Prev. 1 (1): 21-7.

[5] Gronberg, H. 2003. "Prostate Cancer Epidemiology." Lancet 361 (1): 859-64.

[6] Odedina, F. T., Dagne, G., Pressey, S., Odedina, O., Emanuel, F., Scrivens, J., Reams, R. R., Adams, A., and LaRose-Pierre, M. 2011. "Prostate Cancer Health and Cultural Beliefs of Blackmen: The Florida Prostate Cancer Disparity Project." Infectious Agents and Cancer 6 (Suppl 2): $\mathrm{S} 10$.

[7] Delongchamps, N. B., Singh, A., and Haas, G. P. 2007. "Epidemiology of Prostate Cancer in Africa: Another Step in the Understanding of the Disease?" Curr. Probl. Cancer 31 (3): 226-36.

[8] Odedina, F. T., Ogunbiyi, J. O., and Ukoli, F. A. 2006. "Roots of Prostate Cancer in African-American Men." J. Natl. Med. Assoc. 98 (4): 539-43.

[9] Soni, H. C., and Hardin, E. 2016. Prostate Cancer, Causes, Symptoms and Diagnosis. Accessed January 25, 2016. www.emedicinehealth.com

[10] Wynder, L., Mabuchi, K., and Whitmore, W. F. 1971. "Epidemiology of Cancer of the Prostate." Cancer 28 (1): 344-60. 
[11] Haas, G. P., and Sakr, W. A. 1997. "Epidemiology of Prostate Cancer." CA Cancer J. Clin. 47 (1): 273-84.

[12] Jackson, M. A., Ahluwala, B. S., Herson, J., Heshmat, M. Y., Jackson, A. G., Jones, G. W., Kapoor, S. K., Kennedy, J., Kovi, J., Lucas, A. O., Nkposong, E. O., Olisa, E., and Willams, A. O. 1977. "Characterization of Prostatic Carcinoma among Blacks: A Continuation Report." Cancer Treat Rep. 61 (2): 167-72.

[13] Solanke, T. F. 1996. Cancer in Nigeria. Oyo State NMA Annual Guest Lecture, Ibadan.

[14] Ogunbiyi, J. O., and Shittu, O. B. 1999. "Increased Incidence of Prostate Cancer in Nigerians." J. Natl. Med. Assoc. 91 (3): 159-64.

[15] Stewart, B. W., and Kleihues P., ed. 2003. World Cancer Report. Lyon, France: IARC Publication, 208-14.

[16] Parkin, D. M., Whelan, S. L., Ferlay, J., Teppo, L., and Thomas, D. B., ed. 2002. Cancer Incidence in Five Continents Vol VIII. IARC Scientific Publication NO. 155. Lyon, France, IARC Publication, 93-104.

[17] Basset, M. T., Levy, L. M., Chetsanga, C., and Chokunga, E. 1992. "Zimbabwe National Cancer Registry: Summary
Data 1986-1989." Cent. Afr. J. Med. 38 (1): 91-4.

[18] Oluwole, O. P., Rafindadi, H. A., Shehu, M. S., and Samaila, M. O. A. 2015. "A Ten-Year Study of Prostate Cancer Specimens at Ahmadu Bello University Teaching Hospital (A.B.U.T.H) Zaria, Nigeria." African Journal of Urology 21 (1): 15-8.

[19] Boring, C. C., Squires, T. S., and Heath, C. W. Jr. 1992. "Cancer Statistics for African-Americans." CA Cancer J. Clin. 42 (1): 7-17.

[20] Magoha, G. A. 1995. "Epidemiological and Clinical Aspects of Incidental Carcinoma of the Prostate in Africans: Experience at the Lagos University Teaching Hospital, Lagos and the Kenyatta National Hospital, Nairobi." East Afr. Med. J. 72 (5): 283-7.

[21] Akang, E. E., Aligbe, J. U., and Olisa, E. G. 1996. "Prostatic Tumors in Benin City, Nigeria." West Afr. J. Med. 15 (1): 56-60.

[22] Oluwole, O. P., Taiwo, J. O., Awani, K. U., and Adugba, E. O. 2012. "Studies on the Prevalence of Prostate Cancer in Lokoja Metropolis." Adv. Trop. Med. Pub. Health Int. 2 (1): $15-20$. 